\title{
Clinical course and outcomes of COVID-19 in hematopoietic cell transplant patients, a regional report from the Middle East
}

\author{
Riad El Fakih $\mathbb{D D}^{1}$ - Alfadil Haroon ${ }^{1}$ - Feras Alfraih ${ }^{1}$ - Murtadha K. Al-Khabori ${ }^{2}{ }^{2}$ - Mohsen Alzahrani ${ }^{3,4,5}$. \\ Ahmad Alhuraiji ${ }^{6}$ Abdulaziz Hamadah ${ }^{6}$ - Naif I. AlJohani ${ }^{1}$ - Bader Alahmari ${ }^{3,4,5} \cdot$ Mohammed F. Essa ${ }^{4,5,7}$. \\ Ibraheem H. Motabi ${ }^{8}$. Imran K. Tailor ${ }^{8} \cdot$ Reem S. Almaghrabi $^{1}$ - Khalil Al-Farsi ${ }^{2}$ - Ibraheem Abosoudah ${ }^{1}$. \\ Mouhab Ayas $\mathbb{D}^{1} \cdot$ Tusneem A. Elhassan $^{1} \cdot$ Ashraf M. Suhebeh $^{9} \cdot$ Syed Osman Ahmed $^{1} \cdot$ Saud Alhayli $^{1}$.

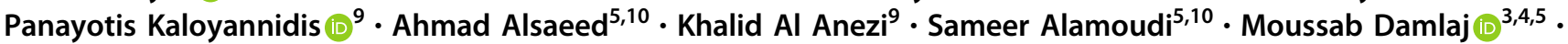 \\ Hani Al Hashmi ${ }^{9}$ Mahmoud Aljurf ${ }^{1}$
}

Received: 3 March 2021 / Revised: 23 March 2021 / Accepted: 12 April 2021 / Published online: 27 April 2021

(c) The Author(s), under exclusive licence to Springer Nature Limited 2021

\begin{abstract}
The coronavirus disease-2019 (COVID-19) caused by SARS Coronavirus 2 (SARS-CoV-2) is a potentially lethal infection. Cancer patients, and specifically hematopoietic cell transplant (HCT) recipients are severely immunocompromised and may be at a higher risk of a complicated course with this infection. We aimed to study the COVID-19 outcomes and severity in post HCT patients. We retrospectively reviewed post-HCT patients diagnosed with COVID-19 between March 15, 2020, and December 1, 2020 at 10 transplant centers across the Middle East. We identified 91 patients with confirmed SARS-CoV2 infection across 10 transplant centers. The median age upon presentation with COVID-19 was 35 . Fifty two patients were post allo-HCT while the remaining 39 patients were post auto-HCT. The median time from transplant was 14.9 months. Mortality rate was $4.4 \%$. Hospital admission rate was $53 \%$. ICU admission rate was $14 \%$. Mechanical ventilation rate was $10 \%$. Oxygen supplementation rate was $18 \%$. Time from HCT to COVID-19>6 months was associated with lower admission rates and lower rates of the "severity" composite endpoint. Antibody responses was seen $67 \%$ of evaluable patients. In this series of HCT recipients, we report overall favorable clinical outcomes for patients with COVID-19 and provide preliminary insights into the clinical course of this disease in this specific population.
\end{abstract}

\section{Introduction}

In December 2019 cases of pneumonia of unknown etiology were reported in Wuhan, China. Eventually, the culprit was identified as the SARS-Coronavirus-2 virus (SARS-CoV-2), and the disease was called coronavirus disease-2019

Riad El Fakih

riadfakih@hotmail.com

1 King Faisal Specialist Hospital and Research Center, Riyadh, Saudi Arabia

2 Sultan Qaboos University, Muscat, Oman

3 King Abdulaziz Medical City, Riyadh, Saudi Arabia

4 King Abdullah International Medical Research Center, Ministry of National Guard, Riyadh, Saudi Arabia

5 King Saud Bin Abdulaziz University for Health Sciences, Riyadh, Saudi Arabia
(COVID-19) [1, 2]. The infection relentlessly spread worldwide causing more than 100 million cases and over 2 million COVID-19-related deaths so far (https://covid19.who.int accessed on 31 January, 2021) [3]. A number of vaccine and therapeutic trials were initiated in parallel with other efforts to better understand every aspect of the virus

6 Department of Hematology Kuwait Cancer Control Centre, Kuwait, Kuwait

7 King Abdullah Specialist Children's Hospital, Ministry of National Guard, Riyadh, Saudi Arabia

8 King Fahad Medical City, Riyadh, Saudi Arabia

9 King Fahad Specialist Hospital, Riyadh, Saudi Arabia

10 King Abdulaziz Medical City, Ministry of National Guard, Jeddah, Saudi Arabia 
(transmission modes, host-susceptibility, complications, symptoms, carriers, etc.) [4-7]. These efforts culminated in the approval of two vaccines so far and a number of medications under the "emergency use authorization" [8, 9] (https://www.fda.gov/emergency-preparedness-and-response/ mcm-legal-regulatory-and-policy-framework/emergency-use -authorization\#coviddrugs). Typically, the disease affects the upper respiratory tract (URT) manifesting as cough, fever among other URT symptoms. However, it can progress and involve the lower respiratory tract (LRT) to cause pneumonia and possibly acute respiratory distress syndrome [10, 11]. Several factors and co-morbidities have been found to correlate with a tendency of a severe course, higher rates of intensive care admission and undesirable outcomes such as age $>60$, lung diseases, hypertension, renal diseases, cancer, diabetes, etc.) [12-23]. Hematopoietic cell transplant (HCT) patients may be an especially vulnerable group. These patients frequently develop lung complications after transplant and often are immunocompromised, so their COVID19 clinical course is expected to be severe. We herein report the course and outcomes of 91 cases of COVID-19 in post allogeneic or autologous HCT patients from ten Middle East centers, we also analyze the impact of different risk factors that may affect the severity of the disease course in this population.

\section{Patients and methods}

\section{Patient population}

HCT recipients who developed COVID-19 post-transplant and reported to ten HCT tertiary care centers in the Middle East. The medical records of these patients were reviewed using the database of each participating institution. Inclusion criteria: HCT recipients (autologous or allogeneic) of any age (pediatric and adult) with laboratory-confirmed COVID-19 by nasal or oropharyngeal swab and polymerase chain reaction (PCR) detection. Exclusion criteria: non HCT patients and patients without PCR confirmation of COVID-19.

\section{Data collection}

a retrospective chart review of HCT recipients who developed COVID-19 and reported to HCT centers in the Middle East. The primary objective was to describe the outcomes and severity of COVID-19 in post-HCT patients by evaluating the hospital admission rate, WHO-severity stage of COVID-19 and a "severity" composite end point consisting of admission rate to the intensive care unit (ICU), need for supplemental oxygen, need for mechanical ventilation (MV) and mortality. The severity stages of COVID-19 were defined as mild, moderate, severe and very severe according the WHO classification [24]. The secondary objectives were to estimate the impact of a number of factors (age, sex, BMI [body mass index], type and number of transplants, type and intensity of the conditioning regimen, being on immunosuppression, current status of the underlying disease, use of prophylactic antimicrobials, time from transplant to COVID-19, underlying comorbidities) on COVID19 outcomes and severity. For the admitted group of patients, we studied the impact of different available laboratory values (WBC [white blood cells], lymphocyte count, neutrophil count, platelet count, ferritin level, ESR [erythrocyte sedimentation rate], CRP [C-reactive protein] and albumin level), and chest X-ray findings on the rates of MV, ICU admission, oxygen need, and mortality. In addition, we studied the number of patients who converted to negative nasopharyngeal swab testing for SARS-CoV-2 by PCR and the number of patients who developed antibodies to SARS-CoV-2 by serology testing in this population. PCR and antibodies testing was carried out every 7 days in tested patients. The hospitals' Institutional Review Board approved the study.

\section{Statistical analysis}

Patient's characteristics were summarized using frequencies with percentages for categorical variables and medians with interquartile range for continuous variables. Association between proposed risk factors and COVID-19 severity was evaluated using Chi-square test. The impact of different proposed risk on COVID-19 severity was evaluated using logistic regression multivariate analysis whenever applicable.

\section{Results}

\section{Patients', underlying disease and transplant characteristics}

A total of 91 patients met the eligibility criteria, the median age upon presentation with COVID-19 was 35 . The median time from transplant to COVID-19 was 14.9 (IQR: 16.3-38.9) months. Thirty-eight patients (42\%) were females and $53(58 \%)$ were males. Forty-seven patients (52\%) had no prior comorbidities while $44(48 \%)$ had prior comorbidities with $15 / 44(34 \%)$ having more than one comorbidity. Fifty-two (57\%) patients had allo-HCT and 39 $(43 \%)$ had an auto-HCT. Twelve (13\%) allo-HCT patients had active GvHD (11 cGvHD and 1 aGvHD) upon COVID19 presentation. Eighty-one $(89 \%)$ patients received myeloablative regimen (MAC) and 10 patients (11\%) underwent reduced intensity conditioning (RIC), 20 patients $(22 \%)$ had 
Table 1 Pre-COVID-19 summary of the patients', underlying disease and HCT characteristics.

\begin{tabular}{|c|c|}
\hline Number of patients & $91(100 \%)$ \\
\hline Median Age upon COVID-19 infection & 35 years \\
\hline$<18$ & $15(16 \%)$ \\
\hline $18-40$ & $32(35 \%)$ \\
\hline$>40$ & $44(48 \%)$ \\
\hline \multicolumn{2}{|l|}{ Sex } \\
\hline Female & $38(42 \%)$ \\
\hline Male & $53(58 \%)$ \\
\hline \multicolumn{2}{|l|}{ BMI } \\
\hline$<30$ & $66(73 \%)$ \\
\hline$>30$ & $24(26 \%)$ \\
\hline missing & $01(01 \%)$ \\
\hline \multicolumn{2}{|l|}{ Comorbidity } \\
\hline None & $47(52 \%)$ \\
\hline Active GvHD & $12(13 \%)$ \\
\hline $\mathrm{DM}$ & $09(10 \%)$ \\
\hline HTN & $06(07 \%)$ \\
\hline Cardiovascular & $04(04 \%)$ \\
\hline Pulmonary & $03(03 \%)$ \\
\hline Other organs dysfunction & $10(11 \%)$ \\
\hline Multiple comorbidities & $15(16 \%)$ \\
\hline \multicolumn{2}{|l|}{ Hematological or underlying disease } \\
\hline Benign & $21(23 \%)$ \\
\hline Leukemia & $27(30 \%)$ \\
\hline Lymphoma & $26(29 \%)$ \\
\hline Myeloma & $16(18 \%)$ \\
\hline Solid tumors & $01(01 \%)$ \\
\hline \multicolumn{2}{|l|}{ Stem cell Transplant type } \\
\hline Allogeneic & $52(57 \%)$ \\
\hline Autologous & $39(43 \%)$ \\
\hline \multicolumn{2}{|l|}{ Number of transplants } \\
\hline One & $81(89 \%)$ \\
\hline Two & $10(11 \%)$ \\
\hline \multicolumn{2}{|l|}{ Conditioning intensity } \\
\hline MAC & $81(89 \%)$ \\
\hline RIC & $10(11 \%)$ \\
\hline \multicolumn{2}{|l|}{ Conditioning type } \\
\hline TBI & $20(22 \%)$ \\
\hline Non-TBI & $70(77 \%)$ \\
\hline Missing & $01(01 \%)$ \\
\hline Median time from HCT to COVID-19 & $\begin{array}{l}14.9 \text { (IQR: } 16.3 \text { to } \\
\text { 38.9) months }\end{array}$ \\
\hline$<6$ months & $23(25 \%)$ \\
\hline 6-12 months & $15(16 \%)$ \\
\hline$>12$ months & $53(59 \%)$ \\
\hline \multicolumn{2}{|c|}{ Prophylactic antimicrobials before COVID-19 } \\
\hline Antiviral & $23(25 \%)$ \\
\hline Antibacterial & $04(04 \%)$ \\
\hline
\end{tabular}

Table 1 (continued)

\begin{tabular}{ll}
\hline Both & $37(41 \%)$ \\
None & $27(30 \%)$ \\
Immunosuppressant upon COVID-19 & \\
No & $42(46 \%)$ \\
Yes & $47(52 \%)$ \\
$\quad$ Missing & $02(02 \%)$ \\
$\begin{array}{l}\text { Disease status } \\
\text { Active }\end{array}$ & $03(03 \%)$ \\
In remission or not applicable (benign & $88(97 \%)$ \\
or solid tumors) & \\
\hline
\end{tabular}

TBI (total body irradiation) based conditioning and 70 (77\%) had non-TBI conditioning. Sixty-four (70\%) patients were on prophylactic antimicrobials and $27(30 \%)$ were not as part of their transplant prophylaxis medications. Fortyseven (52\%) patients were on immunosuppressive medications (tacrolimus, cyclosporine, mycophenolate mofetil, and/or steroids) while $42(46 \%)$ were not. The majority of patients (88 patients or $97 \%$ ) were in remission, while three patients (3\%) had active disease at the time of COVID-19. Table 1 is a pre-COVID-19 summary of the patients', underlying disease and HCT characteristics.

\section{Patient's treatment, clinical and paraclinical characteristics during COVID-19}

Upon confirming the diagnosis, $78(86 \%)$ patients had symptoms while $13(14 \%)$ patients were asymptomatic (these patients were tested after a household member tested positive, all reported subjective fever when presenting for testing but we could not document objective fever). The most frequent symptoms on presentation were fever in 51 patients (56\%), followed by cough in 37 patients $(41 \%)$ and shortness of breath in 22 patients (24\%). Forty-four (48\%) patients received COVID-19 directed therapies while 47 (52\%) did not. Sixty-two (68\% of total patients) had a chest $\mathrm{X}$-ray, of these $36(58 \%)$ were abnormal (presence of infiltrates or consolidation). Seventy-one (78\%) patients had WBC count check, of these 27 (38\%) had lower than normal level and 9 (13\%) had higher than normal level. Seventy-one (78\%) patients had platelet count check, of these $32(45 \%)$ had lower than normal level and $2(3 \%)$ had higher than normal level. Sixty-nine $(76 \%)$ patients had lymphocyte count check, of these $36(52 \%)$ had lower than normal level and 2 (3\%) had higher than normal level. Sixty-nine $(76 \%)$ patients had neutrophil count check, of these 21 (30\%) had lower than normal level and 9 (13\%) had higher than normal level. Fifty-seven $(63 \%)$ patients had albumin level check, of these 44 (77\%) had lower than normal level. Forty-five patients (49\%) had ferritin level 
Table 2 summary of the patients' treatment, clinical and paraclinical characteristics during COVID-19.

\begin{tabular}{|c|c|}
\hline \multicolumn{2}{|l|}{ Patient symptoms } \\
\hline Symptomatic & $78(86 \%)$ \\
\hline Asymptomatic & $13(14 \%)$ \\
\hline \multicolumn{2}{|l|}{ Presenting symptoms } \\
\hline Fever & $51(56 \%)$ \\
\hline Cough & $37(41 \%)$ \\
\hline SOB & $22(24 \%)$ \\
\hline Runny nose & $18(20 \%)$ \\
\hline Fatigue & $17(19 \%)$ \\
\hline Throat pain & $12(13 \%)$ \\
\hline Headache & $10(11 \%)$ \\
\hline $\begin{array}{l}\text { Diarrhea, vomiting, loss of smell, dizziness, } \\
\text { myalgia abdominal pain and chest pain }\end{array}$ & $<10 \%$ \\
\hline \multicolumn{2}{|l|}{ COVID-19 and associated infections therapy } \\
\hline Azithromycin & $05(05 \%)$ \\
\hline Hydrochloroquine & $00(00 \%)$ \\
\hline Azithromycin + Hydrochloroquine & $10(11 \%)$ \\
\hline Antibiotics & $21(23 \%)$ \\
\hline Steroids & $06(07 \%)$ \\
\hline Others & $02(02 \%)$ \\
\hline None & $47(52 \%)$ \\
\hline Chest X-ray & $\begin{array}{l}62(68 \% \text { of total } \\
\text { patients })\end{array}$ \\
\hline Normal & $26(42 \%)$ \\
\hline Abnormal & $36(58 \%)$ \\
\hline White blood cell count & $\begin{array}{l}71(78 \% \text { of total } \\
\text { patients })\end{array}$ \\
\hline Normal & $35(49 \%)$ \\
\hline High & $09(13 \%)$ \\
\hline Low & $27(38 \%)$ \\
\hline Lymphocyte count & $\begin{array}{l}69(76 \% \text { of total } \\
\text { patients) }\end{array}$ \\
\hline Normal & $31(45 \%)$ \\
\hline High & $02(03 \%)$ \\
\hline Low & $36(52 \%)$ \\
\hline Neutrophil count & $\begin{array}{l}69(76 \% \text { of total } \\
\text { patients) }\end{array}$ \\
\hline Normal & $39(57 \%)$ \\
\hline High & $09(13 \%)$ \\
\hline Low & $21(30 \%)$ \\
\hline Platelet count & $\begin{array}{l}71(78 \% \text { of total } \\
\text { patients })\end{array}$ \\
\hline Normal & $37(52 \%)$ \\
\hline High & $02(03 \%)$ \\
\hline Low & $32(45 \%)$ \\
\hline Ferritin level & $\begin{array}{l}45(49 \% \text { of total } \\
\text { patients) }\end{array}$ \\
\hline Normal & $12(27 \%)$ \\
\hline High & $30(67 \%)$ \\
\hline
\end{tabular}

Table 2 (continued)

\begin{tabular}{ll}
\hline Low & $03(06 \%)$ \\
ESR level & $32(35 \%$ of total \\
& patients $)$ \\
Normal & $08(25 \%)$ \\
High & $24(75 \%)$ \\
CRP level & $52(57 \%$ of total \\
& patients $)$ \\
Normal & $07(13 \%)$ \\
High & $45(87 \%)$ \\
Albumin level & $57(63 \%$ of total \\
& patients $)$ \\
Normal & $13(23 \%)$ \\
Low & $44(77 \%)$ \\
\hline
\end{tabular}

check, of these 30 (67\%) had higher than normal level. Fifty-two (57\%) patients had CRP level check, of these 45 $(87 \%)$ had higher than normal level. Table 2 provides a detailed summary of the patients' treatment, clinical and paraclinical characteristics during COVID-19.

\section{Outcomes}

Forty-five (50\%) patients had mild, $32(35 \%)$ had moderate, $5(5 \%)$ had severe and $9(10 \%)$ had very severe WHOCOVID-19 stage. Forty-eight (53\%) patients needed admission to the hospital and $43(47 \%)$ were managed at home with supportive measures. Of the 48 admitted patients, 13 (16\% of the total and $31 \%$ of the admitted patients) needed ICU admission, 16 (18\% of the total and $33 \%$ of the admitted patients) needed oxygen supplementation, 9 (10\% of the total and $19 \%$ of the admitted patients) needed mechanical ventilation and 4 (4.4\% of the total and $8.3 \%$ of the admitted patients) died. The cause of death was sepsis secondary to multidrug resistant bacteria ( 2 Klebsiella, one Acinetobacter and one Pseudomonas). Looking at mortality according to specific subgroups, one patient died in the group of patient transplanted within 6 months of HCT and 3 patients died in the group transplanted $>12$ months from COVID-19, three auto-HCT died and one allo-HCT, one patient died in the group of patients younger than 18, one in the group of patients aged 18-40 and two died in the group of patients older than 40 years. Nine patients $(10 \%$ of the total and $19 \%$ of the admitted patients) developed acute kidney injury and only one had line associated thrombosis. Sixty-six patients had serial (weekly) follow up nasopharyngeal-swab PCR, 51 one of them converted to negative PCR at a median time of 37 days (14-116 days). Twenty-seven patients were checked for the presence of anti-SARS-CoV-2 antibodies, 18 of them tested positive at a median time of 34 days. These outcomes are summarized in Table 3. 
Table 3 Outcomes of HCT patients after COVID-19.

\begin{tabular}{ll}
\hline COVID-19 stage & \\
Mild & $45(50 \%)$ \\
Moderate & $32(35 \%)$ \\
Severe & $05(05 \%)$ \\
Very severe & $09(10 \%)$ \\
Admission & \\
Yes & $48(53 \%)$ \\
No & $43(47 \%)$ \\
ICU admission & \\
Yes & $13(14 \%)$ \\
No & $78(86 \%)$ \\
Mechanical ventilation & \\
Yes & $09(10 \%)$ \\
No & $82(90 \%)$ \\
Oxygen supplementation & \\
Yes & $16(18 \%)$ \\
No & $75(82 \%)$ \\
Patient status & \\
Alive & $87(95.6 \%)$ \\
Dead & $04(4.4 \%)$ \\
Follow up nasopharyngeal-swab PCR & $66(72.5 \%)$ \\
Negative & $51(77 \%)$ \\
Positive & $15(23 \%)$ \\
Anti-SARS-CoV-2 antibodies & $27(30 \%)$ \\
Negitive & $18(67 \%)$ \\
ThI & $9(33 \%)$ \\
\hline & $09(10 \%)$ \\
Nhrombosis & $01(01 \%)$ \\
\hline
\end{tabular}

\section{Impact of different risk factors on COVID-19 severity outcomes for all 91 patients}

The hospital admission rate for COVID-19 patients transplanted within 6 months was $73.9 \%$ compared to $45.6 \%$ for COVID-19 patients transplanted in more than 6 months ( $p$ value $=0.02)$, with an $\mathrm{OR}=9.04$ (95\%.CI: $1.5-13.6)(p$ value $=0.001)$. Patients who were not on any prophylactic antimicrobials (as part of their transplant treatment course) before infection with SARS-CoV-2 had an admission rate of $74 \%$ as compared to $48.1 \%$ for patients on a combination of anti-virial and antibacterial $(p$ value $=0.038$ ). Patients who were receiving antivirals only were at higher risk of hospital admission compared to those on a combination (antiviral and antibacterial) prophylaxis (OR $=9.2(95 \%$. CI: $2.5-34.08), p$ value $=0.001$ ). For the "severity" composite end point, patients transplanted within 6 months were at higher risk compared to patients transplanted in more than 6 months of COVID-19 (34.8\% vs.16.2\%), $p$ value $=$ 0.05 . All the other analyzed risk factors (age, sex, BMI, type, and number of transplants, type and intensity of the conditioning regimen, being on immunosuppression, current status of the underlying disease and underlying comorbidities) did not have a significant association with the studied outcomes (WHO-severity stage of COVID-19 and the "severity" composite end point). Multivariate analysis revealed that time from HCT to COVID-19 infection and prophylactic treatment were significantly associated with the hospital admission in multivariate analysis ( $p$-value $=0.001$ and 0.004 , respectively). As mentioned in the methods section, for the subgroup of patients admitted to the hospital we studied the impact of the same risk factors in addition to the chest X-ray findings and the available laboratory values upon admission on the rates of mechanical ventilation, ICU admission, oxygen need and mortality. $43 \%$ of patients with high neutrophil count required MV, while no patient with low neutrophil count required MV and $16.4 \%$ of patients with normal neutrophil count needed MV $(p$ value $=0.037) .70 \%$ of males compared to $13 \%$ of females required ICU admission $(p$ value $=0.036$ ). Ninety three $\%$ of patients with abnormal chest X-ray required oxygen therapy while, $53 \%$ of patients with normal chest $\mathrm{X}$-ray required oxygen therapy $(p$ value $=0.01) .33 \%$ of patients with very severe COVID-19 infection died.

\section{Discussion}

With data emerging about the detrimental course of certain patients' subgroups with this infection, particularly cancer patients [18-23], we were interested to study a special group of patients that is known to have a complicated course with infections, the post HCT group of patients. With around 90 thousand HCT carried out annually and around 1.5 million post-HCT patients worldwide, a significant number of these can develop COVID-19 [25, 26]. The impact of this new infection on this specific subgroup of patients is largely unknown. The cases reported early in the course of the pandemic were alarming, but this can be attributed to reporting bias [27-29]. Case series were then reported. A pediatric transplant group reported the outcomes of 8 patients, five of them $(62.5 \%)$ were admitted to the hospital and 2 needed ICU care, one patient died (12.5\%) [30]. The first consecutive 11 post-HCT patients with COVID-19 presenting to our center had a smooth course, five of seven tested patients developed anti SARS$\mathrm{CoV} 2$ antibodies and all of them recovered [26]. However, HCT-patients are a heterogeneous group and the HCT procedure is very complex, so drawing firm conclusions from a small number of patients is impossible. Larger datasets were then published. A report from Spain included a mix of hematologic malignancies and transplant patients (58 post auto-HCT and 65 post allo-HCT) showed that 
transplant recipients had lower mortality compared to hematologic malignancies patients $(17 \%$ for auto-HCT, $18 \%$ for allo-HCT and $31 \%$ for hematologic malignancies patients, $p=0.02$ ). Additionally, uncontrolled hematological malignancy, neutropenia, limited performance status, age $>70$ and elevated CRP were associated with higher mortality for the whole group, not for the transplant patients specifically [31]. Another study reported on 14 auto-HCT and 20 allo-HCT patients with a median time to COVID-19 of 17.4 months. $41 \%$ had > moderate WHO-COVID-19 severity stage, chest X-ray infiltrates were found in $75 \%$ of patients, $74 \%$ of patients were hospitalized, $32 \%$ needed ICU admission with $73 \%$ of them needing intubation and mortality was $21 \%$. Age $>40$, being on steroid prior to COVID-19, transplant within 1 year, hemoglobin $<10 \mathrm{~g} / \mathrm{dl}$ and platelet count $<150\left(\times 10^{9} / \mathrm{L}\right)$ significantly increased mortality [32]. A study from Italy, reported a mortality of $35 \%$ and $33 \%$ in post allo-HCT and post auto-HCT patients, respectively [33]. Memorial Sloan Kettering Cancer Center reported the outcomes of 77 cellular therapy patients (35 post allo-HCT, 37 post auto-HCT and 5 post chimeric antigen receptor-T cell therapy). Thirty day mortality was $22 \%$ with significantly worse course (defined as death and nonrebreather oxygen mask) in patients with comorbidities, infiltrates on chest X-ray and neutropenia. The mortality rate for hospitalized patients was $41 \%$ (thought to be driven by active malignancy cases). The outcomes were not different based on the underlying hematologic malignancy. Thirty-eight patients $(49 \%)$ had antibody testing done at a median of 37 days after diagnosis with $66 \%$ of those developing antibodies. $50 \%$ of their patients were managed as outpatient. The time from cellular therapy did not impact the outcomes in their analysis [34]. The largest reported series to date comes from the Center for International Blood and Marrow Transplant Research (CIBMTR) recent report [35] (of note some patients included in that analysis might have been previously reported in the other two published North American cohorts [32, 34]). Of the 318 reported transplant recipients $82 \%$ were diagnosed by nasal swab PCR, $2 \%$ based on symptoms and $15 \%$ had no diagnostic method reported; 184 were allo-HCT (36\% MSD, 27\% MUD, $37 \%$ alternate donor, and $18 \%$ were receiving immunosuppression within 6 months of COVID-19) and 134 were auto-HCT recipients. The median time from HCT to COVID-19 diagnosis was 17 months for allo-HCT and 23 months for auto-HCT recipients. The median age was 47 years for allo-HCT and 60 years for auto-HCT recipients. $49 \%$ had mild disease while mechanical ventilation was required in $14 \%$ of patients. At 30 days after COVID-19, OS was $68 \%$ and $67 \%$ for allo-HCT and auto-HCT patients respectively. Male sex, age $>50$, and COVID-19 within 12 months of HCT were associated with a higher risk of mortality among allo-HCT recipients. Lymphoma, as the underlying disease, was associated with a higher risk of mortality compared with plasma cell disorder or myeloma in auto-HCT recipients. Absolute lymphocyte count $<0.3 \times$ $10^{9}$ cells/L at COVID-19 diagnosis was associated with worse survival. Race, ethnicity, HCT-comorbidity index, and immunosuppression in the 6 months before COVID-19 were not associated with increased mortality [35].

We aimed to collect a larger number of patients and variables to better understand the impact of this pandemic on post-HCT patients. The majority of patients were symptomatic $(86 \%)$, with fever, cough and shortness of breath being the top three presenting symptoms. The mortality rate was $4.4 \%$, which is lower than all the reported series [31-35], despite the fact that a comparable number of our patients required ICU admission and MV. This can be explained by a number of factors, namely the younger age of our cohort and lower comorbidity rates (52\% had no comorbidities and only $10 \%$ had DM). Important to note that all the patients reported in this cohort were treated in tertiary care centers, where access to advanced care was easier compared to other countries where the health care systems were overwhelmed by the high numbers of COVID-19. As reported in other series, we confirm the time from HCT to COVID-19 is significantly associated with worse outcomes [32, 35]. For the subgroup of admitted patients high neutrophil count was associated with higher need for MV, this finding is probably a surrogate of severe inflammation or associated bacterial infection. Admitted males required more ICU admission in our series and this is in line of the worst outcomes in males reported by the CIBMTR study [35], and other non-HCT studies showing a skewed infectivity and increased mortality in males [13, 36, 37]. As expected, we report that patients with abnormal chest X-ray findings required more oxygen supplementation and patients with very severe COVID-19 stage had a high mortality rate $(33.3 \%)$. Our study, in line with others [34], shows that around two third of HCT-patients are able to mount an antibody response (with a median time of 34 days) and around $77 \%$ will convert to PCR negative (with a median time of 37 days), despite earlier reports suggesting that these patients may not develop antibodies and stay PCR positive long time [38]. In line with a number of other reports but not all [30-32, 34], our data show that mortality is lower than the mortality in hematologic malignancies patients [33, 39] and the mortality of solid organ transplant patients [40-42] but higher than the mortality in the general population. This may be explained by the selective selection of fit and young patients to undergo HCT and by the theoretical lower intensity of lung inflammation from the impaired immune response in HCT patients. Important to note the relatively young age of our reported cohort (median age of 35), and the fact that the majority of our patients had the COVID-19 infection more 
than 12 months after transplant (median time between COVID-19 presentation and transplant was 14.9 months).

\section{Conclusion}

We report a comprehensive description of the outcomes of hematopoietic cell recipients after COVID-19. This analysis provides a deeper understating of this pandemic in this subgroup of patients. An extensive list of possible factors that impact the severity of COVID-19 were analyzed. Our study suffers from the usual limitations of retrospective studies; however the fact that it exclusively included HCT patients with a modest yet reasonable number and a comprehensive set of data, it helps in drawing important conclusions and set the stage to investigate further research questions related to COVID-19 in HCT patients, such as the effect of immune reconstitution on COVID-19 outcomes, the impact of immunosuppression and the lack of immune response obviating the severe spectrum of the COVID-19 disease, etc. Finally, awaiting effective therapies and a better understanding of this infection, we urge to apply and stress the importance of preventive measures. We recommend large scale vaccination for patients, their families and caretakers according to the published guidelines by transplant societies (www.ebmt.org/ sites/default/files/2020-12/COVID\%20vaccines\%20version\% $202.03 \% 20$ with\%20table.pdf). We could not assess the effects of COVID-19 directed therapies on the outcomes of our patients due to the rapidly changing therapeutic protocols and the limited number of patients on each protocol.

Acknowledgements We thank the Saudi Society for Blood Disorders (SSBD) for the general supervision of the study conduct and for the administrative support provided.

\section{Compliance with ethical standards}

Conflict of interest The authors declare no competing interests.

Publisher's note Springer Nature remains neutral with regard to jurisdictional claims in published maps and institutional affiliations.

\section{References}

1. Lu H, Stratton CW, Tang Y-W. Outbreak of pneumonia of unknown etiology in Wuhan, China: the mystery and the miracle. J Med Virol. 2020;92:401-2.

2. Chen N, Zhou M, Dong X, Qu J, Gong F, Han Y, et al. Epidemiological and clinical characteristics of 99 cases of 2019 novel coronavirus pneumonia in Wuhan, China: a descriptive study. Lancet. 2020;395:507-13.

3. World Health Organization. Coronavirus disease 2019 (COVID19): situation report, 82. 2020.

4. Ortiz-Prado E, Simbana-Rivera K, Gomez-Barreno L, RubioNeira M, Guaman LP, Kyriakidis NC, et al. Clinical, molecular and epidemiological characterization of the SARS-CoV2 virus and the Coronavirus disease 2019 (COVID-19), a comprehensive literature review. Diagnostic Microbiol Infect Dis. 2020;98:115094.

5. World Health Organization. Informal consultation on prioritization of candidate therapeutic agents for use in novel coronavirus 2019 infection. 2020. In, 2020.

6. Lurie N, Saville M, Hatchett R, Halton J. Developing Covid-19 vaccines at pandemic speed. N Engl J Med. 2020;382:1969-73.

7. Bhatti JS, Bhatti GK, Khullar N, Reddy AP, Reddy PH. Therapeutic strategies in the development of anti-viral drugs and vaccines against SARS-CoV-2 infection. Mol Neurobiol. 2020;57:1-22. https://doi.org/10.1007/s12035-020-02074-2.

8. Polack FP, Thomas SJ, Kitchin N, Absalon J, Gurtman A, Lockhart S, et al. Safety and efficacy of the BNT162b2 mRNA Covid-19 vaccine. N Engl J Med. 2020;383:2603-15.

9. Oliver SE. The Advisory Committee on Immunization Practices' Interim Recommendation for Use of Moderna COVID-19 vaccine —United States, 2020. MMWR. 2020; 69.

10. Adhikari SP, Meng S, Wu Y-J, Mao Y-P, Ye R-X, Wang Q-Z, et al. Epidemiology, causes, clinical manifestation and diagnosis, prevention and control of coronavirus disease (COVID-19) during the early outbreak period: a scoping review. Infect Dis poverty. 2020;9:1-12.

11. Cummings MJ, Baldwin MR, Abrams D, Jacobson SD, Meyer BJ, Balough EM, et al. Epidemiology, clinical course, and outcomes of critically ill adults with COVID-19 in New York City: a prospective cohort study. Lancet. 2020;395:1763-70.

12. Arentz M, Yim E, Klaff L, Lokhandwala S, Riedo FX, Chong M, et al. Characteristics and outcomes of 21 critically ill patients with COVID-19 in Washington State. JAMA. 2020;323:1612-4.

13. Yang X, Yu Y, Xu J, Shu H, Liu H, Wu Y, et al. Clinical course and outcomes of critically ill patients with SARS-CoV-2 pneumonia in Wuhan, China: a single-centered, retrospective, observational study. Lancet Respir Med. 2020;8:475-81.

14. Liu W, Tao Z-W, Wang L, Yuan M-L, Liu K, Zhou L, et al. Analysis of factors associated with disease outcomes in hospitalized patients with 2019 novel coronavirus disease. Chin Med J. 2020. https://doi.org/10.1097/CM9.0000000000000775.

15. Wang D, Hu B, Hu C, Zhu F, Liu X, Zhang J, et al. Clinical characteristics of 138 hospitalized patients with 2019 novel coronavirus-infected pneumonia in Wuhan, China. JAMA. 2020;323:1061-9.

16. Yang J, Zheng Y, Gou X, Pu K, Chen Z, Guo Q, et al. Prevalence of comorbidities in the novel Wuhan coronavirus (COVID-19) infection: a systematic review and meta-analysis. Int J Infect Dis. 2020;94:91-5.

17. Huang C, Wang Y, Li X, Ren L, Zhao J, Hu Y, et al. Clinical features of patients infected with 2019 novel coronavirus in Wuhan, China. Lancet. 2020;395:497-506.

18. Miyashita H, Mikami T, Chopra N, Yamada T, Chernyavsky S, Rizk D, et al. Do patients with cancer have a poorer prognosis of COVID-19? An experience in New York City. Ann Oncol. 2020;31:1088-89.

19. Guan W-J, Liang W-H, Zhao Y, Liang H-R, Chen Z-S, Li Y-M, et al. Comorbidity and its impact on 1590 patients with Covid-19 in China: a nationwide analysis. Eur Respir J. 2020;55:2000547.

20. He W, Chen L, Chen L, Yuan G, Fang Y, Chen W, et al. COVID19 in persons with haematological cancers. Leukemia. 2020;34:1637-45. https://doi.org/10.1038/s41375-020-0836-7.

21. Gavillet M, Klappert JC, Spertini O, Blum S. Acute leukemia in the time of COVID-19. Leuk Res. 2020;92:106353.

22. Dai M, Liu D, Liu M, Zhou F, Li G, Chen Z, et al. Patients with cancer appear more vulnerable to SARS-COV-2: a multicenter study during the COVID-19 outbreak. Cancer Discov. 2020;10:783-91. 
23. ElGohary GM, Hashmi S, Styczynski J, Kharfan-Dabaja MA, Alblooshi RM, de la Camara R, et al. The risk and prognosis of COVID-19 infection in cancer patients: a systematic review and meta-analysis. Hematol/Oncol Stem Cell Ther. 2020. https:// doi.org/10.1016/j.hemonc.2020.07.005.

24. World Health Organization. Clinical management of COVID-19: interim guidance, 2020. World Health Organization, 2020.

25. Niederwieser D, Baldomero H, Atsuta Y, Aljurf M, Seber A, Greinix HT, et al. One and half million hematopoietic stem cell transplants (HSCT). Dissemination, trends and potential to improve activity by telemedicine from the Worldwide Network for Blood and Marrow Transplantation (WBMT). In: American Society of Hematology Washington, DC, 2019.

26. Haroon AAM, Aljurf M, Ahmed SO, Shaheen M, Hanbli A, Chaudhari N, et al. COVID-19 post hematopoietic cell transplant, a report of 11 cases from a single center. Mediterranean J Hematol Infect Dis. 2020;12:e2020070-e2020070.

27. Onaka T, Iwai F, Kato-Ogura A, Yonezawa A. Severe acute respiratory syndrome coronavirus-2 (SARS-CoV-2) infection after allogeneic stem cell transplantation. Clin Case Rep. 2020;8:1791-92.

28. Lu X, Tang LV, Wang H-F, You Y, Wang Y-D, Hu Y, et al. The great challenge of managing recipients of hematopoietic stem cell transplantation combined with COVID-19. Bone Marrow Transpl. 2020:1-5.

29. Huang J, Lin H, Wu Y, Fang Y, Kumar R, Chen G, et al. COVID19 in posttransplant patients a report of 2 cases. Am J Transpl. 2020;20:1879-81.

30. Vicent MG, Martinez AP, Del Castillo MT, Molina B, Sisini L, Moron-Cazalilla G, et al. COVID-19 in pediatric hematopoietic stem cell transplantation: the experience of Spanish Group of Transplant (GETMON/GETH). Pediatr Blood Cancer 2020;67:e28514.

31. Pinana JL, Martino R, Garcia-Garcia I, Parody R, Morales MD, Benzo G, et al. Risk factors and outcome of COVID-19 in patients with hematological malignancies. Exp Hematol Oncol. 2020 25;9:21. https://doi.org/10.1186/s40164-020-00177-z. eCollection 2020. 2020

32. Varma A, Kosuri S, Ustun C, Ibrahim U, Moreira J, Bishop MR et al. COVID-19 infection in hematopoietic cell transplantation: age, time from transplant and steroids matter, Leukemia. 2020;34:2809-12. https://doi.org/10.1038/s41375-020-01019-x. Epub 2020 Aug 14, 2020.
33. Passamonti F, Cattaneo C, Arcaini L, Bruna R, Cavo M, Merli F, et al. Clinical characteristics and risk factors associated with COVID-19 severity in patients with haematological malignancies in Italy: a retrospective, multicentre, cohort study. Lancet Haematol. 2020;7:e737-745.

34. Shah GL, DeWolf S, Lee YJ, Tamari R, Dahi PB, Lavery JA, et al. Favorable outcomes of COVID-19 in recipients of hematopoietic cell transplantation. J Clin Invest. 2020;130:6656-67.

35. Sharma A, Bhatt NS, St Martin A, Abid MB, Bloomquist J, Chemaly RF, et al. Clinical characteristics and outcomes of COVID-19 in haematopoietic stem-cell transplantation recipients: an observational cohort study. Lancet Haematol. 2021;8: e185-93.

36. Kuderer NM, Choueiri TK, Shah DP, Shyr Y, Rubinstein SM, Rivera DR, et al. Clinical impact of COVID-19 on patients with cancer (CCC19): a cohort study. Lancet. 2020;395: 1907-18.

37. Richardson S, Hirsch JS, Narasimhan M, Crawford JM, McGinn T, Davidson KW, et al. Presenting characteristics, comorbidities, and outcomes among 5700 patients hospitalized with COVID-19 in the New York City area. JAMA. 2020;323:2052-9.

38. Zamperlini-Netto G, Fernandes JF, Garcia JL, Ribeiro AAF, Camargo LFA, de Moraes Terra C, et al. COVID-19 after hematopoietic stem cell transplantation: report of two children. Bone Marrow Transpl. 2020;56:713-5.

39. Wood WA, Neuberg DS, Thompson JC, Tallman MS, Sekeres MA, Sehn LH, et al. Outcomes of patients with hematologic malignancies and COVID-19: a report from the ASH Research Collaborative Data Hub. Blood Adv. 2020;4:5966-75.

40. Malekhosseini SA, Nikoupour H, Gholami S, Shamsaeefar A, Arasteh P, Kazemi K, et al. A report of 85 cases of COVID-19 and abdominal transplantation from a single center: what are the associated factors with death among organ transplantation patients. Transplantation. 2020;105:90-9.

41. Sharma P, Chen V, Fung CM, Troost JP, Patel VN, Combs M, et al. COVID-19 outcomes among solid organ transplant recipients: a case-control study. Transplantation. 2020;72: 269A-70A.

42. Nair V, Jandovitz N, Jhaveri KD, Molmenti E. COVID-19 and solid organ transplant outcomes. Nephrol Dial Transpl. 2020;35:1444-6. 